CLINICAL STUDY

\title{
Monocentric study of 112 consecutive patients with childhood onset GH deficiency around and after transition
}

\author{
Carine Courtillot ${ }^{1,2}$, Roselyne Baudoin ${ }^{1,2}$, Tatiana Du Souich ${ }^{1,2}$, Lucile Saatdjian ${ }^{1,2}$, Isabelle Tejedor ${ }^{1,2}$, \\ Graziella Pinto $^{3,4}$, Juliane Léger ${ }^{5,6}$, Michel Polak ${ }^{3,4}$, Jean-Louis Golmard ${ }^{2,7}$, Philippe Touraine ${ }^{1,2}$ \\ on behalf of the Transition GHD Group ${ }^{\dagger}$ \\ ${ }^{1}$ AP-HP, Hôpital Pitié-Salpêtrière, Endocrinologie et Médecine de la Reproduction, 47-83, Boulevard de l'Hôpital, Paris F-75013, France, ${ }^{2}$ Université \\ Pierre et Marie Curie Paris 06, Paris F-75013, France, ${ }^{3}$ AP-HP, Hôpital Necker-Enfants Malades, Endocrinologie Pédiatrique, Paris F-75015, France, \\ ${ }^{4}$ Université Paris Descartes Paris 05, Paris F-75006, France, ${ }^{5}$ AP-HP, Hôpital Robert Debré, Endocrinologie Pédiatrique et Diabétologie, Paris F-75019, \\ France, ${ }^{6}$ Université Paris Diderot Paris 07, Paris F-75010, France and ${ }^{7}$ AP-HP, Unité de Recherche Clinique, Hôpital Pitié-Salpêtrière, \\ Paris F-75013, France
}

(Correspondence should be addressed to P Touraine at AP-HP, Hôpital Pitié-Salpêtrière, Endocrinologie et Médecine de la Reproduction; Email: philippe.touraine@psl.aphp.fr)

${ }^{\dagger}$ (Details of the Transition GHD Group is given in the Acknowledgements section.)

\begin{abstract}
Objectives: Our aim was to analyze a large cohort of childhood onset GH deficiency (CO-GHD) adults from a unique adult center, in order to analyze their clinical management and to study the metabolic and bone status in relation to GHD and to the other pituitary deficits, and to evaluate these parameters during the long-term follow-up.

Design and methods: Observational retrospective cohort study on 112 consecutive CO-GHD adults transferred to our unit from 1st January 1994 to 1st March 2012. Evaluation of GHD in pediatrics and after transition was conducted following consensus guidelines. Data recorded from pediatric and adult files were GH doses, pituitary magnetic resonance imaging and function, and metabolic and bone status. Results: Most patients presented with severe CO-GHD (64\%) associated with other pituitary deficits (66\%). CO-GHD was acquired in 56\%, congenital in 33\%, and idiopathic in $11 \%$ cases. Most patients $(83 \%)$ stopped GH before transfer, at 16.3 years (median), despite persistence of GHD. Median age at transfer was 19.4 years. After transfer, GHD persisted in 101 patients and four of the 11 resolutive GHD were non idiopathic. IGF1 level was $<-2$ SDS in $70 \%$ of treated patients at transfer and in $34 \%$ of them after 3 years of treatment. Follow-up showed improvement in lipid profile and bone mineral density in severely persistent GHD patients under GH therapy. In multivariate analysis, the associated pituitary deficits seemed stronger determinant factors of metabolic and bone status than GHD.

Conclusions: This study raises concern about discontinuation of GH replacement therapy in pediatrics in severely persistent GHD patients and about the often insufficient dose of GH in the treatment of adult patients.
\end{abstract}

European Journal of Endocrinology 169 587-596

\section{Introduction}

The optimal management of GH deficiency (GHD) during childhood, through adolescence, and all along adulthood is a challenge to pediatric and adult endocrinologists. In childhood, reduced linear growth is the primary consequence of untreated GHD and historically GH replacement therapy (GHRT) was stopped once final height was achieved. During the last decade, there has been a growing body of literature describing the negative impact of GHD on body composition, bone health, metabolic profile, cardiovascular risk, and quality of life, in older adolescents and in adults, pleading for a maintenance of GHRT in young adults with persistent GHD $(1,2)$. All of our knowledge on the long-term management of childhood onset GHD (CO-GHD) patients, once they become adults, relate to either large but multicentric studies $(3,4,5,6,7,8)$ or to monocentric studies on small cohorts $(9,10,11)$. There is a lack of large monocentric studies addressing this issue.

Our adult endocrinological department is involved in the management of patients with rare endocrine disorders. We decided to study the consecutive CO-GHD patients transferred to our unit by all our collaborating pediatric departments, from 1994 to 2012. Our aim was to analyze the first large cohort of CO-GHD adults from a unique adult center, in order to evaluate their clinical management and to study their metabolic and bone status in relation to GHD and to the other pituitary deficits, and the evaluation of these parameters during long-term follow-up. 


\section{Subjects and methods}

\section{Patients}

This observational retrospective cohort study took place in the adult department of endocrinology and reproductive medicine in Pitie-Salpetriere Hospital, Paris, France. The identities of all patients with CO-GHD transferred to our unit have been listed prospectively in a database since 2006. At that time, we retrieved, from the common database system of our hospital, the identities of the patients with CO-GHD transferred to us since 1994, and retrospectively added them to our database.

In our study, we included CO-GHD patients, transferred from any pediatric department to our unit, from 1st January 1994 to 1 st March 2012, and who had at least one evaluation in our department.

CO-GHD was defined following the consensus guidelines (12). A peak GH concentration below $20 \mathrm{mUI} / \mathrm{l}$ after a provocative test was the threshold for defining GHD. Severe GHD was considered for peak $\mathrm{GH}$ concentration below $10 \mathrm{mUI} / \mathrm{l}$ and partial GHD for peak GH concentration between 10 and $20 \mathrm{mUI} / \mathrm{l}$.

In pediatrics, provocative $\mathrm{GH}$ tests performed were arginine +insulin $(n=36)$, ornithine $(n=15)$, glucagon + betaxolol $(n=13)$, insulin tolerance test (ITT; $n=8)$, clonidine $(n=2)$, or L-dopa $(n=2)$. During childhood, most patients with a suspected isolated GHD had two provocative tests and most patients with a CNS pathology, a history of irradiation, or multiple pituitary deficits had one provocative test. We recorded in our database only the results from one stimulation test in pediatrics. For some patients $(n=16)$, the type of stimulation test used was unknown, but we had a pediatric report with the peak value of $\mathrm{GH}$. In the other cases $(n=20)$, we had a pediatric report concluding to a GHD but we did not have the test results.

After transfer to our adult department, GHD was re-evaluated after a discontinuation of GH therapy of at least 1 month. The provocative test used was the ITT. During the transition period, a peak GH concentration below $15 \mathrm{mUI} / \mathrm{l}$ after ITT was considered as severe GHD (partial if peak $\mathrm{GH}$ between 15 and $20 \mathrm{mUI} / \mathrm{l}$ ), following the 2005 consensus (13).

Other pituitary functions were also evaluated. Gonadotropic deficiency was defined by an absence of spontaneous pubertal development at the physiologic age for puberty, and low estradiol (for girls) or testosterone (for boys) associated with low gonadotrophins (FSH and $\mathrm{LH}$ ) after pubertal induction. Thyreotropic deficiency was defined by free thyroxine $\left(\mathrm{FT}_{4}\right)$ below normal range with TSH under upper normal range. Corticotropic deficiency was defined by plasma cortisol response to ITT or Synacthene $0.25 \mathrm{mg}$ below $415 \mathrm{nmol} / \mathrm{l}$, with normal or low ACTH. Lactotropic deficiency was defined by prolactin under normal range, after puberty. The presence of a diabetes insipidus was assessed by a water restriction test of at least $12 \mathrm{~h}$.
In all patients, a pituitary magnetic resonance imaging (MRI) was carried out to search for malformation, tumor, or infiltration of the hypothalamicpituitary region.

\section{Pediatric data}

We went to the different pediatric departments in order to have direct access to the pediatric files. Files were reviewed for age, gender, results of GH stimulation tests and insulin-like growth factor 1 (IGF1) level, assessment of other anterior and posterior pituitary deficits, and MRI results of the pituitary. For patients for whom we could retrieve from the pediatric files, the information about GH treatment during childhood, age and dose at initiation, and pattern and duration of treatment was noted. Final and target heights ( $\mathrm{cm}$ and SDS) were recorded.

\section{Transition data}

Age at last consult in the pediatric department and age at first consult in the adult department were noted. The same data as in childhood were recorded concerning the evaluation of pituitary function. If $\mathrm{GH}$ was resumed, dose and age were noted. If GH was stopped, reasons were specified.

\section{Adult data}

Data recorded in the adult department were pituitary function (IGF1 level and evaluation of other pituitary deficits), treatment with GH (dose, observance, and side effects), anthropometric measurements (weight, height, and BMI), metabolic parameters (lipid profile, fasting glycemia (FG), HbAlc, and body composition assessment by dual-energy X-ray absorptiometry (DEXA)), and bone metabolism parameters (osteocalcin and bone mineral density (BMD) assessment by DEXA).

We recorded GH doses and IGF1 levels at each visit (consultation or hospitalization). For all the other parameters, we recorded the results from the evaluations (EVAL) performed during hospitalizations. By definition, all patients had at least one evaluation during hospitalization in our department.

For patients with severe persistent GHD, at the first evaluation in our department (EVAL1), we compared the parameters of EVAL1 with those recorded at the second evaluation (EVAL2), the closest to 3 years after EVAL1. The patients with severe persistent GHD at transition, who have undergone EVAL1 and EVAL2, were divided into two groups: group 1 being the patients who received GH therapy (either continuously or discontinuously) between EVAL1 and EVAL2, and group 2 being the patients who did not receive $\mathrm{GH}$ therapy between EVAL1 and EVAL2.

We analyzed the recorded parameters based on IGF1 SDS values, and compared patients with IGF1 <-2 
SDS with patients with IGF $1 \geq-2$ SDS. We also studied the influence, of all the recorded parameters, of the pituitary deficits associated with the GHD.

\section{Hormonal assays}

The level of IGF1 was measured using immunoradiometric assay (CIS Bio, Gif sur Yvette, France). Results were expressed in nanomoles per liter and in Z-score (SDS). As the IGF1 values were not normally distributed, IGF1 SDS calculation was done after log transformation $(\ln )$.

\section{Statistical analysis}

Descriptive statistics used numbers and percentages for qualitative variables and means and S.D.s or medians and inter-quartile intervals (Q1-Q3) for quantitative ones. Distributions of actual following times and maximum potential following times were estimated by the Kaplan-Meier method. Differences between two groups were tested using $\chi^{2}$ tests or Fisher's exact tests for qualitative variables and two-sample Wilcoxon tests for quantitative ones. Paired comparisons between EVAL1 and EVAL2 distributions were tested using McNemar tests for qualitative variables and signedrank tests for quantitative ones. Relationships between two quantitative variables were assessed using Spearman's rank correlation coefficient tests. Multivariate analyses aimed at finding the relationships between each biological variable and the types of deficit, and were performed using linear models estimated using stepwise regression. All tests were two-sided, with a $P$ value $<0.05$ considered as significant. Computations were performed using the SAS V9 statistical package.

\section{Results}

\section{Description of the cohort and pediatric data}

We reviewed the files of 112 consecutive patients with CO-GHD transferred to our unit, with at least one evaluation during hospitalization. We did not have direct access to 20 pediatric files, but did not exclude them because we obtained the reports of pediatric hospitalization that concluded the presence of CO-GHD (all of these 20 patients were re-evaluated in the adult department and they had persistent GHD).

Patients (62\% men and 38\% women) mostly had severe GHD, usually associated with other pituitary deficits and due in a majority of cases to an acquired or a congenital cause (Table 1). Seventy-six percent of the congenital GHDs were due to pituitary malformation, and $48 \%$ of the acquired GHD were secondary to craniopharyngioma (data not shown).

Information about GH doses, age at initiation, and discontinuation, in the pediatric department, were available only for 96 patients $(86 \%)$. Median age at initiation of $\mathrm{GH}$ was 10.0 years (6.3-13.9), median initial GH doses were $=34.7 \mu \mathrm{g} / \mathrm{kg}$ per day $(27.6-38.8)$ (after 5 years $=31.4 \mu \mathrm{g} / \mathrm{kg}$ per day $(24.4-34.5)$ ).

Eighty of the 96 patients (83\%) stopped GH before being transferred to the adult department, at a median age of 16.3 years (14.7-17.3). Among those 80 patients, 39 had a dynamic re-evaluation of the somatotropic axis in the pediatric department, showing persistent GHD in 36 of them.

Median target height was 0.8 SDS ( -0.8 to 0.7 ). Median final height was -0.2 SDS ( -0.9 to 0.4 ). Median difference between median target and final heights was -0.17 SDS ( -1.0 to 0.6 ). Final height was $<-2$ SDS in three women and four men. There was no difference in final height in either sex according to the etiology of the GHD.

\section{Transition period}

Median age at the last visit in the pediatric department was 19.1 years (16.1-27.3) and median age at first visit in the adult department was 19.4 years (18.4-21.3). Median time between last visit in pediatrics and first visit in the adult department was 4.6 months (2.6-6.7). Sex, etiology of GHD, year of transition, age at transfer, and time lapse between last visit in the pediatric department and first visit in the adult department were not correlated (data not shown).

Median time between the end of GH treatment in pediatrics department and first evaluation (EVAL1) in the adult department was 3.4 years (1.7-5.8) and all patients

Table 1 Degree of GHD and its association with other pituitary deficits, according to the etiology, at evaluation in the pediatric department.

\begin{tabular}{lcccc}
\hline CO-GHD & $\begin{array}{c}\text { Whole cohort } \\
(n=112)\end{array}$ & $\begin{array}{c}\text { Acquired } \\
56 \%(n=63)\end{array}$ & $\begin{array}{c}\text { Congenital } \\
33 \%(n=37)\end{array}$ & $\begin{array}{c}\text { Idiopathic } \\
11 \%(n=12)\end{array}$ \\
\hline $\begin{array}{l}\text { Degree of GHD } \\
\text { Severe }\end{array}$ & $64 \%(72 / 112)$ & $64 \%(40 / 63)$ & $73 \%(27 / 37)$ & $42 \%(5 / 12)$ \\
Partial & $18 \%(20 / 112)$ & $14 \%(9 / 63)$ & $16 \%(6 / 37)$ & $42 \%(5 / 12)$ \\
$\quad$ Missing data & $18 \%(20 / 112)$ & $22 \%(14 / 63)$ & $11 \%(4 / 37)$ & $16 \%(2 / 12)$ \\
$\begin{array}{l}\text { Pituitary deficits } \\
\text { Multiple deficits* }\end{array}$ & $66 \%(74 / 112)$ & $65 \%(41 / 63)$ & $76 \%(28 / 37)$ & $42 \%(5 / 12)$ \\
Isolated GHD & $22 \%(25 / 112)$ & $19 \%(12 / 63)$ & $22 \%(8 / 37)$ & $42 \%(5 / 12)$ \\
Missing data & $12 \%(13 / 112)$ & $16 \%(10 / 63)$ & $2 \%(1 / 37)$ & $16 \%(2 / 12)$ \\
\hline
\end{tabular}


who stopped GH in childhood did so for more than 6 months when they arrived in the adult department. Patients who did not discontinue $\mathrm{GH}$ before transfer were re-evaluated between 1 and 2 months after GH withdrawal, according to consensus guidelines.

\section{Follow-up in the adult department}

GH status at EVAL1 During transition, at their first evaluation (EVAL1) in the adult department, 90 patients had an ITT to re-evaluate the somatotropic axis (Fig. 1). The 22 others did not: they had organic disease with at least three additional pituitary hormone deficiencies and IGF1 level $<-2$ SDS.

Among the 90 re-tested patients, 79 (88\%) had a persistent GHD (71 patients had a peak GH below $15 \mathrm{mUI} / \mathrm{l}$, considered as severe GHD during the transition period, and eight patients had a peak $\mathrm{GH}$ between 15 and $20 \mathrm{mUI} / \mathrm{l}$, considered as partial GHD during the transition period). The remaining 11 patients had a restored normal response of $\mathrm{GH}$ secretion in response to ITT (GH peak > $20 \mathrm{mUI} / \mathrm{l}$ ): seven with an idiopathic GHD, two with an ectopic neurohypophysis (one with interrupted stalk), one with an empty sella, and one with Langerhans cell histiocytosis.

In all, we considered that $101(=79+22)$ patients had persistent GHD at the first evaluation in our department, comprising $93(=71+22)$ patients with an indication to resume GHRT according to consensus guidelines. The number of patients who received $\mathrm{GH}$ at some point during adult follow-up was 49 .

At EVAL1, 33 patients with persistent GHD were treated with GH (currently or with a withdrawal of $<1$ month): 16 had not stopped since pediatrics and the other ones had restarted at first consult in the adult department, before first evaluation. In treated patients, median GH dose was $0.60 \mathrm{mg} /$ day (0.4-1). IGF1 level was $<-2$ SDS in $23(70 \%)$ of the treated patients (median IGF $1=-3.3$ SDS $(-4.2$ to -2.9$)$ ) with median GH doses of $0.60 \mathrm{mg} /$ day (0.50 to 0.85$)$. IGF1 level was $\geq-2$ SDS in the other $10(30 \%)$ patients treated (median IGF1 $=-0.8$ SDS $(-1.1$ to 0.9$)$ ) with the median GH doses of $0.6 \mathrm{mg} /$ day $(0.6$ to 0.8$)$. There was no significant difference between the doses of GH in patients with IGF1 $<-2$ SDS compared with patients with IGF $1 \geq-2$ SDS $(P=0.6)$. However, it is important to note that among the $13 / 33$ patients with the highest $\mathrm{GH}$ doses $(\geq 1 \mathrm{mg} /$ day), six of them had very poor observance. In the 20/33 remaining patients (with GH doses $<1 \mathrm{mg} /$ day), only three had observance issues.

At EVAL1, 97\% of patients declared no side effect of GH treatment, but the information was lacking in 70\% of the files. Fifteen patients had a history of seizures, and only one reported seizure aggravated under GH therapy.

Among the $68 \mathrm{GHD}$ patients who were not $\mathrm{GH}$ treated at EVAL1, IGF1 was $<-2$ SDS in $75 \%$, with a median IGF1 of -3.9 SDS $(-4.3$ to -3.4$)$. IGF1 was $\geq-2$ SDS in the other $25 \%$, with a median IGF1 of -1.1 SDS $(-1.7$ to -0.6$)$.

\section{Evaluation of recorded parameters according to the} treatment group Sixty-three patients with severe persistent GHD (peak GH $<15 \mathrm{mUI} / \mathrm{l}$ ) at the first evaluation, at transition in the adult unit, had more than one evaluation in our department.

Median time between EVAL1 and EVAL2 was 2.5 years (1.6-3.3). For 39/63 patients, EVAL2 took place within 2-4 years after the transfer.

Patients in group $1(n=45)$ were treated with $\mathrm{GH}$ either continuously or discontinuously between EVAL1 and EVAL2. Patients treated discontinuously had a median time under $\mathrm{GH}$ between both evaluations of $40 \%$, meaning that the median time under $\mathrm{GH}$ between

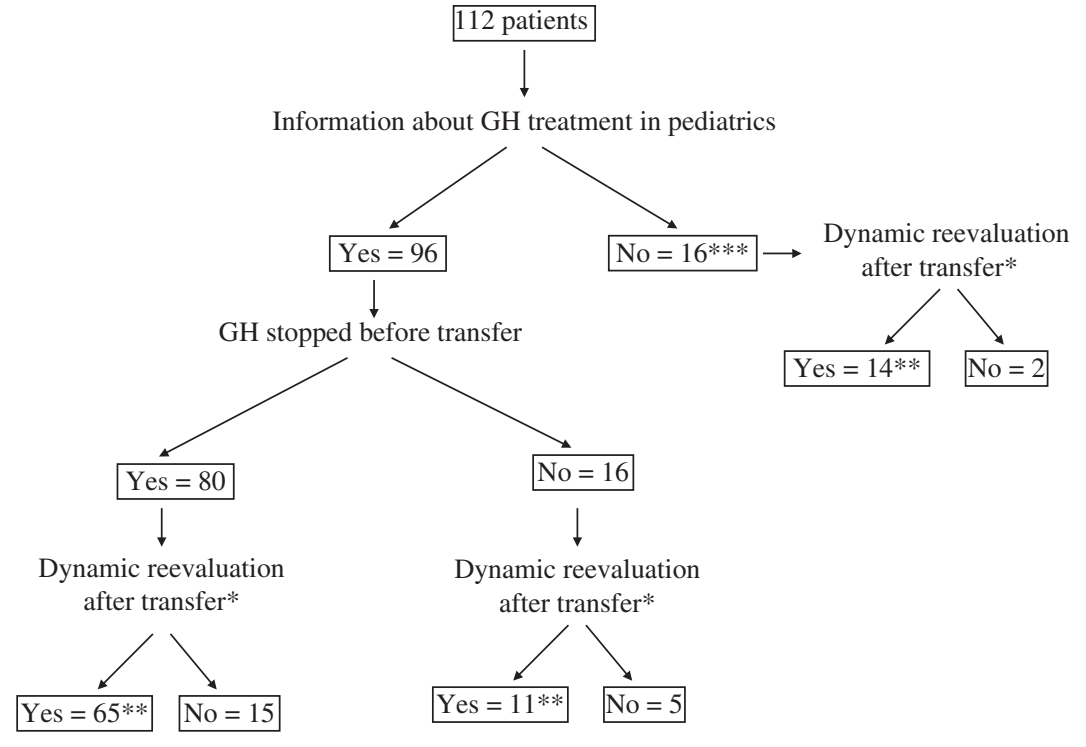

Figure $1 \mathrm{GH}$ treatment and reevaluation of $\mathrm{GH}$ axis after transfer. Proportion of patients who stopped GH treatment in pediatrics and number of patients who had a dynamic reevaluation of the somatotropic function at their first evaluation in the adult department. ${ }^{*}$ Dynamic reevaluation, insulin tolerance test. **Number of patients with a dynamic reevaluation of the somatotropic function after transfer, 90. ${ }^{* \star *}$ None under GH therapy at the first evaluation in the adult department. 
EVAL1 and EVAL2 was a little less than half of the time between the two evaluations. Patients in group 2 $(n=18)$ had an indication for GHRT, but did not wish to resume this treatment.

Table 2 shows the clinical practice of how many patients of each group had each of the recorded parameters at both the evaluations. We compared the two groups at EVAL1, at EVAL2, and the evaluation of all parameters within and between each group between EVAL1 and EVAL2. Results are shown in Table 3.

GH status. Doses of GH were obviously different between the two groups, at each hospitalization. In group 1 , there was no significant difference in doses between EVAL1 and EVAL2; however, doses tended to decrease.

IGF1 SDS values were not significantly different between group 1 and group 2 at EVAL1; however, they were significantly different at EVAL2 $(P=0.005)$. In group 1 , there was a rise in median IGF1 of 1.8 SDS, which was significant $\left(P=10^{-4}\right)$. In group 2, IGF1 SDS values were not significantly different between EVAL1 and EVAL2.

At EVAL1, IGF1 value was $<-2$ SDS in $70 \%$ of patients in group 1 and in $73 \%$ of patients in group 2 $(P=1)$. At EVAL2, IGF1 was $<-2$ SDS in $34 \%$ of patients in group 1 and in $69 \%$ of patients in group $2(P=0.02)$. The difference in the proportion of patients with IGF1 $<-2$ SDS in group 1, between EVAL1 $(70 \%)$ and EVAL2 (34\%) was strongly significant $\left(P=7 \times 10^{-4}\right)$.

Anthropometric parameters. Patients in group 1 were significantly younger and taller than patients in group 2 at each evaluation. No one significantly grew between EVAL1 and EVAL2, but in group 1 patients tended to grow $(P=0.055)$. Weight and BMI were not different between the groups at each hospitalization; however, they rose significantly in both groups between EVAL1 and EVAL2. Although patients in group 2 tended

Table 2 Number of patients with available data at each evaluation.

\begin{tabular}{|c|c|c|c|c|}
\hline \multirow{2}{*}{$\begin{array}{l}\text { Available } \\
\text { parameters }\end{array}$} & \multicolumn{2}{|c|}{ Group $1(n=45)$} & \multicolumn{2}{|c|}{ Group $2(n=18)$} \\
\hline & EVAL1 & EVAL2 & EVAL1 & EVAL2 \\
\hline Height, weight & $100 \%(45)$ & $100 \%(45)$ & $100 \%(18)$ & $100 \%(18)$ \\
\hline Lipid profile & $91 \%(41)$ & $98 \%(44)$ & $83 \%(15)$ & $94 \%(17)$ \\
\hline Fasting glycemia & $96 \%(43)$ & $89 \%(40)$ & $89 \%(16)$ & $100 \%(18)$ \\
\hline $\mathrm{HbA1c}$ & $47 \%(21)$ & $64 \%(29)$ & $28 \%(5)$ & $67 \%(12)$ \\
\hline $\begin{array}{l}\text { Body composition } \\
\text { (DEXA) }\end{array}$ & $33 \%(15)$ & $31 \%(14)$ & $6 \%(1)$ & $33 \%(6)$ \\
\hline Osteocalcin & $56 \%(25)$ & $60 \%(27)$ & $33 \%(6)$ & $50 \%(9)$ \\
\hline $\begin{array}{l}\text { Bone mineral } \\
\text { density (DEXA) }\end{array}$ & $67 \%(30)$ & $49 \%(22)$ & $39 \%(7)$ & $33 \%(6)$ \\
\hline
\end{tabular}

EVAL1, first evaluation in the adult department (at transfer from the pediatric department); EVAL2, second evaluation in the adult department (the closest possible to 3 years after transfer); Group 1, adult patients with persistent severe GHD who received (continuously or discontinuously) GH between EVAL1 and EVAL2; Group 2, adult patients with persistent severe GHD who never had GH between EVAL1 and EVAL2. to put on more weight than in group 1, the difference was not significant.

Metabolic parameters. Evaluation of total cholesterol (TC) showed a significantly difference between the two groups (it dropped by a median of $-0.15 \mathrm{mmol} / \mathrm{l}$ in group 1 and raised by a median of $0.3 \mathrm{mmol} / \mathrm{l}$ in group $2, P<0.05$ ).

The same trend was observed for triglycerides (TG) and LDL-c, without reaching statistical significance, once adjusted for sex and BMI. No significant difference was found regarding the body composition once adjusted for sex and height (data not shown).

FG was higher in group 2 at each time, and difference between the two groups was almost significant at EVAL1. FG rose between EVAL1 and EVAL2 in both the groups, but it was not significant once adjusted for BMI. HbA1c was lower in group 1 than that in group 2 at EVAL2, but it lost significance once adjusted for BMI.

Bone metabolism. We observed a significant rise in spine and hip BMD in group 1 between EVAL1 and EVAL2. However, at each hospitalization there was no difference between the two groups and the modification of the BMD between the two hospitalizations was not different between the two groups. No statistical difference was found for osteocalcin (data not shown).

Other comparisons. We also compared all the parameters between EVAL1 and EVAL2, by dividing the patients with severe persistent GHD at transition and who had a second evaluation $(n=63)$ differently. On one hand, we compared patients always under $\mathrm{GH}$ vs patients never under $\mathrm{GH}$ vs patients taking $\mathrm{GH}$ discontinuously. On the other hand, we compared patients always under $\mathrm{GH}$ vs patients taking $\mathrm{GH}$ discontinuously pooled with patients never under $\mathrm{GH}$. We found no significant difference for any of the studied parameters for any of these comparisons (data not shown).

\section{Comparison of the recorded parameters according}

to IGF1 We compared all the parameters at EVAL1 and EVAL2 according to IGF1 SDS values, whether they were $<-2$ or $\geq-2$ SDS (data not shown). Surprisingly, doses of $\mathrm{GH}$ were not significantly related to IGF1 SDS values. None of the recorded parameters were significantly linked to IGF1 SDS values, apart from osteocalcin level at EVAL2, which was significantly lower in patients with low IGF1 (median: $22 \mathrm{ng} / \mathrm{ml}$ (7-47) vs $35 \mathrm{ng} / \mathrm{ml}(29-55), P=0.04)$. The sex ratio of patients with IGF1 $<-2$ SDS was 1 at both evaluations.

Influence of the associated pituitary deficits We studied the correlations of all the quantitative variables to the number of pituitary deficits associated to the GHD. Significant results are presented in Table 4 . The number of pituitary deficits was strongly correlated between EVAL1 and EVAL2 $\left(r=0.92, P<10^{-4}\right)$. At EVAL1, TC, TG, LDL-c, weight, BMI, and percentage of fat mass were positively correlated to the number of pituitary deficits 
Table 3 Comparison of recorded parameters according to the treatment group at both evaluations. For each studied parameter, only when the data were not available for all patients, we indicated the number of patients for whom they were available.

\begin{tabular}{|c|c|c|c|c|}
\hline & \multicolumn{2}{|c|}{ EVAL1 } & \multicolumn{2}{|c|}{ EVAL2 } \\
\hline & $\begin{array}{c}\text { Group } 1 \\
\text { Median (Q1-Q3) }(n=45)\end{array}$ & $\begin{array}{c}\text { Group 2 } \\
\text { Median (Q1-Q3) }(n=18)\end{array}$ & $\begin{array}{c}\text { Group } 1 \\
\text { Median (Q1-Q3) }(n=45)\end{array}$ & $\begin{array}{c}\text { Group 2 } \\
\text { Median (Q1-Q3) }(n=18)\end{array}$ \\
\hline GH dose (mg/day) & $\begin{array}{c}0.60^{*}(0.4 \text { to } 1) \\
(n=15)\end{array}$ & $0^{*}$ & $\begin{array}{c}0.60^{\dagger}(0.4 \text { to } 0.8) \\
(n=35)\end{array}$ & $0^{\dagger}$ \\
\hline IGF1 (SDS) & $-3^{\ddagger}(-3.8$ to -1.5$)$ & $\begin{array}{c}-3.8(-4.2 \text { to }-1.9) \\
(n=15)\end{array}$ & $-1.5^{\dagger, \neq}(-2.3$ to -0.1$)$ & $\begin{array}{c}-2.8^{\dagger}(-3.6 \text { to }-1.6) \\
(n=16)\end{array}$ \\
\hline Age (years) & $19.3^{*}(18.4$ to 21.2$)$ & $21.8^{\star}$ (19.4 to 22.6$)$ & $21.5^{\dagger}$ (20.5 to 23.6$)$ & $24.8^{\dagger}(21.8$ to 27.9$)$ \\
\hline Height (SDS) & $0.2^{*}(-0.8$ to -0.5$)$ & $-0.8^{*}(-2.2$ to 0.2$)$ & $0.2^{\dagger}(-0.7$ to -0.8$)$ & $-0.9^{\dagger}(-2.1$ to -0.2$)$ \\
\hline Weight (kg) & $72.8^{\ddagger}(62$ to 91$)$ & $65^{\S}(59$ to 72$)$ & $73^{\ddagger}(67$ to 94$)$ & $69.5^{\S}(61$ to 81$)$ \\
\hline $\mathrm{BMI}\left(\mathrm{kg} / \mathrm{m}^{2}\right)$ & $24.9^{\ddagger}(22.7$ to 30.2$)$ & $23.9^{\S}(20.8$ to 29.4$)$ & $25.2^{\ddagger}(23.8$ to 30.6$)$ & $25.7^{\S}(22$ to 31.5$)$ \\
\hline $\mathrm{TC}^{\mathrm{a}}(\mathrm{mmol} / \mathrm{l})$ & $\begin{array}{c}4.84 \begin{array}{c}(4.10 \text { to } 5.60) \\
(n=41)\end{array}\end{array}$ & $\begin{array}{c}4.90(4.35 \text { to } 5.80) \\
(n=15)\end{array}$ & $\begin{array}{c}4.81(4.07 \text { to } 5.51) \\
(n=44)\end{array}$ & $\begin{array}{c}5.07(4.66 \text { to } 6.21) \\
(n=17)\end{array}$ \\
\hline $\mathrm{TG}^{\mathrm{a}}(\mathrm{mmol} / \mathrm{l})$ & $\begin{array}{c}0.83(0.60 \text { to } 1.49) \\
(n=41)\end{array}$ & $\begin{array}{c}0.86(0.59 \text { to } 1.80) \\
(n=15)\end{array}$ & $\begin{array}{c}1.07(0.72 \text { to } 1.84) \\
(n=44)\end{array}$ & $\begin{array}{c}1.16(0.79 \text { to } 2.60) \\
(n=17)\end{array}$ \\
\hline LDL-c ${ }^{a}(\mathrm{mmol} / \mathrm{l})$ & 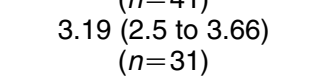 & $\begin{array}{c}2.56(2.29 \text { to } 3.88) \\
(n=7)\end{array}$ & $\begin{array}{c}2.82(2.43 \text { to } 3.56) \\
(n=37)\end{array}$ & $\begin{array}{c}2.84(2.48 \text { to } 3.55) \\
(n=13)\end{array}$ \\
\hline $\mathrm{FG}^{\mathrm{b}}(\mathrm{mmol} / \mathrm{l})$ & $\begin{array}{c}3.90(3.7 \text { to } 4.5) \\
(n=43)\end{array}$ & $\begin{array}{c}4.45(4 \text { to } 4.95) \\
(n=16)\end{array}$ & $\begin{array}{c}4.30(4.05 \text { to } 4.60) \\
(n=40)\end{array}$ & 4.65 (3.9 to 5$)$ \\
\hline $\mathrm{HbA} 1 \mathrm{c}^{\mathrm{b}}(\%)$ & $\begin{array}{c}5.3(5.1 \text { to } 5.5) \\
(n=21)\end{array}$ & $\begin{array}{c}5.3(5.2 \text { to } 5.6) \\
(n=5)\end{array}$ & $\begin{array}{c}5.3(5.1 \text { to } 5.5) \\
(n=29)\end{array}$ & $\begin{array}{c}5.6(5.45 \text { to } 5.8) \\
(n=12)\end{array}$ \\
\hline BMD spine $\left(\mathrm{g} / \mathrm{cm}^{2}\right)$ & $\begin{array}{c}0.96^{\ddagger}(0.84 \text { to } 1.08) \\
(n=32)\end{array}$ & $\begin{array}{c}0.93(0.84 \text { to } 1.0) \\
(n=6)\end{array}$ & $\begin{array}{c}0.97^{\ddagger}(0.87 \text { to } 1.11) \\
(n=22)\end{array}$ & $\begin{array}{c}0.95(0.9 \text { to } 1.04) \\
(n=15)\end{array}$ \\
\hline BMD hip $\left(\mathrm{g} / \mathrm{cm}^{2}\right)$ & $\begin{array}{c}0.94^{\ddagger}(0.83 \text { to } 1.04) \\
(n=32)\end{array}$ & $\begin{array}{c}0.83(0.81 \text { to } 0.87) \\
(n=6)\end{array}$ & $\begin{array}{c}0.98^{\ddagger}(0.93 \text { to } 1.11) \\
(n=22)\end{array}$ & $\begin{array}{c}0.96(0.86 \text { to } 1.04) \\
(n=15)\end{array}$ \\
\hline
\end{tabular}

EVAL1, first evaluation in the adult department (after transfer from the pediatric department); EVAL2, second evaluation in the adult department (the closest possible to 3 years after transfer); Group 1, patients who received GH between EVAL1 and EVAL2; Group 2, patients who never had GH between EVAL 1 and EVAL2; TC, total cholesterol; TG, triglycerides; FG, fasting glycemia; BMD, bone mineral density. This table compares the studied parameters between treated (group 1) and untreated (group 2) patients at first evaluation after transfer (EVAL1) and at second evaluation (EVAL2) in the adult department. It also compares the evolution of these parameters between EVAL1 and EVAL2 in each group. The symbols indicate a significant difference $(P<0.05)$ for each comparison: *significant difference between group 1 and group 2 at EVAL1; ${ }^{\dagger}$ significant difference between group 1 and group 2 at EVAL2; ${ }^{\ddagger}$ significant difference between EVAL1 and EVAL2 for group 1; and \$significant difference between EVAL1 and EVAL2 for group 2.

${ }^{\mathrm{a}}$ Adjusted on sex and BMI.

${ }^{\mathrm{b}}$ Adjusted on BMI.

associated with the GHD. At EVAL2, we found the same correlation for TC, weight and BMI, but it lacked significance for TG and LDL-c.

We finally studied all the parameters, for which we found significant differences at EVAL1 or at EVAL2, in a multivariate analysis to determine which was the strongest determinant among the following: corticotropic, thyreotropic, gonadotropic deficiencies, diabetes insipidus, treatment group (group 1 or 2), and IGF1 status $(<-2$ or $\geq-2$ SDS).

None of the parameters was significantly linked to treatment group or to IGF1 status in multivariate analysis. The gonadotropic deficiency was found to be significantly linked to TC at EVAL1 and EVAL2 $\left(P=4 \times 10^{-4}\right.$ and 0.01 respectively), TG at EVAL1 $(P=0.001)$, weight at EVAL1 and EVAL2 $\left(P=8 \times 10^{-4}\right.$ and 0.002 respectively), and BMI at EVAL1 and EVAL2 $\left(P<10^{-4}\right.$ and $8 \times 10^{-4}$ respectively). The corticotropic deficiency was found significantly linked to FG at EVAL1 $(P=0.02)$, fat mass percentage at EVAL1 $(P=0.01)$, hip $Z$-score $(P=0.006$, even though it was in the opposite direction than expected), and IGF1 at EVAL2 $(P=0.004)$. Thyreotropic deficiency was significantly linked to LDL-c at EVAL1 $(P=0.02)$; and diabetes insipidus was significantly linked to fat mass percentage at EVAL1 $(P=0.04)$.

Comparison of recorded parameters according to the etiology of GHD Among the 63 patients with severe persistent GHD, who had at least two evaluations, 44 had an acquired GHD and 15 a congenital

Table 4 Correlations of all the studied quantitative variables to the number of pituitary deficits associated with the GHD.

\begin{tabular}{|c|c|c|c|c|}
\hline & \multicolumn{2}{|c|}{ EVAL1 } & \multicolumn{2}{|c|}{ EVAL2 } \\
\hline & $r$ & $P$ & $r$ & $P$ \\
\hline IGF1 SDS & \multicolumn{2}{|c|}{ NS } & \multicolumn{2}{|c|}{ NS } \\
\hline Weight & 0.41 & 0.001 & 0.39 & 0.002 \\
\hline BMI & 0.42 & $5 \times 10^{-4}$ & 0.36 & 0.005 \\
\hline Fat mass (\%) & 0.81 & $10^{-4}$ & & \\
\hline $\mathrm{TC}$ & 0.30 & 0.03 & 0.32 & 0.01 \\
\hline TG & 0.34 & 0.01 & & \\
\hline LDL-C & 0.39 & 0.02 & & \\
\hline HDL-c & \multicolumn{2}{|c|}{ NS } & & \\
\hline$F G$ & -0.35 & 0.01 & & \\
\hline Z-score hip & 0.58 & 0.02 & & \\
\hline
\end{tabular}

TC, total cholesterol; TG, triglycerides; FG, fasting glycemia; $r$, correlation; NS, non significant. 
GHD. We compared all the qualitative and quantitative parameters at EVAL1 and at EVAL2, and their evaluation between EVAL1 and EVAL2, in acquired vs congenital GHD patients. The parameters which reached significance were the presence of a diabetes insipidus being more frequent in acquired GHD (none was observed in congenital GHD; $P=10^{-5}$ ), LDL-c being higher at EVAL1 in acquired than congenital GHD (median 3.22 (2.60-3.96) vs 2.29 (1.86-2.54), $P=0.02)$, and FG being higher at EVAL2 in congenital than in acquired GHD (median 4.7 (43-5.3) vs 4.2 (3.95-4.55), $P=0.02$ ).

Follow-up During their follow-up in the adult department, $63 \%$ of patients came at least once a year and $76 \%$ of patients visited our unit within the last 2 years. Seventeen percent of patients were lost to follow-up 1 year after the transfer. Up to 10 years after the transfer, less than one-third of the patients were lost to follow-up (data not shown).

\section{Discussion}

This study shows how 112 consecutive CO-GHD adults are taken care of, around and after the transition period. The advantage of this study is that all patients have been transferred and followed-up in a unique adult department, though they came from different pediatric units.

Most patients (two-thirds) had severe GHD in childhood, associated with other pituitary deficits, which is in a close proportion to what has been observed in other studies (12). Idiopathic GHD is less frequent in our study than that in others $(5,11)$, but it is not surprising because in most cases these patients recover a normal somatotropic function (14) and thus are not transferred to an adult department.

Our patients were transferred around the age 19, which seems appropriate. Indeed, it is suggested that transfer should be organized at the time of another change in the adolescent life, for example, the end of school (15). This age is close to what was observed in other studies of transitioning CO-GHD patients $(5,11)$ and to the age considered as ideal by patients in an autoquestionnaire (16). In this study, age at transfer is independent from etiology, sex, or year of transfer. Patients treated with GH during young adulthood (group 1) are transferred at a younger age than patients with persistent GHD who are not treated with $\mathrm{GH}$ during adulthood (group 2), regardless of the etiology. This suggests that the pediatric team organizes transfer sooner for patients who do not discontinue GH in pediatrics or who agree to the idea of resumption.

Median time between last consult in the pediatric department and first consult in the adult department was short (4.6 months), showing that when transition was prepared, there was a continuity in care around transfer. After transfer, most patients were regularly followed, with less than one-third of patients lost to follow-up. The success of transition was mandatory for patients with chronic conditions, such as CO-GHD, in order to optimize long-term follow-up and medical outcome $(17,18)$.

There has been a lot of concern about the impact of discontinuation of GH during transition, even after reaching adult height, leading to adverse effects on lipid profile, body composition, other cardiovascular risk factors, and acquisition of peak bone mass $(4,10,19)$. Several studies have shown benefit from not interrupting GHRT at this point in time $(4,6,7,9,19,20)$. In our cohort of CO-GHD patients, GHRT was discontinued before transfer in most patients, even though they had persistent $\mathrm{GHD}$, raising concern about their full bone and body composition maturation. Some of them continued to be followed in pediatrics several years before transfer. These observations could be taken into account by pediatricians when deciding whether to stop GH at the end of adolescence or not, and when considering the most adequate time for transfer. However, we noticed differences in pediatric management according to the various departments from which our patients came.

Transition period is an appropriate time for reassessment of GH status, unless there is high likelihood of persistent GHD (1). Four patients with non-idiopathic GHD have recovered a normal response of GH secretion in response to stimulation, two of which having an etopic neurohypophysis, a finding which has already been described (21).

Patients under GHRT at first evaluation in the adult department (EVAL1) had a GH dose about 50\% lower than the recommended pediatric dose $(25 \mu \mathrm{g} / \mathrm{kg}$ per day) and close to the recommended doses around transition (between 12.5 and $25 \mu \mathrm{g} / \mathrm{kg}$ per day or even lower, depending on authors) (13, 14, 22, 23). The currently recommended doses during transition are possibly insufficient. Indeed, in our study $70 \%$ of treated patients at EVAL1 had IGF1 values $<-2$ SDS, independent of the sex. However, most of the patients with the highest doses of GH showed poor observance. It is most surprising that patients under GHRT with IGF1 values $<-2$ SDS have a dose of GH similar to those of patients with IGF1 values $\geq-2$ SDS, but this can be explained by the fact that three patients with low IGF1 have the highest doses prescribed and severe observance issues.

In patients with severe persistent GHD, IGF1 SDS values are significantly higher in the treated group (group 1) than in the non-treated group (group 2) at EVAL2, which is consistent with the fact that IGF1 level is correlated to GH treatment $(6,24)$, but this is not the case at EVAL1. The rise in IGF1 SDS values in the treated group between both evaluations is significant and there are significantly fewer patients with IGF1 values $<-2$ SDS in the treated group at EVAL2 than at 
EVAL1. There is an improvement in the efficiency of the treatment in time, probably linked to the fact that doses of GH were more appropriate in older patients, and to the fact that patients who continue GHRT for years during adulthood are motivated and show better observance than in late adolescence.

In CO-GHD adult patients with persistent GHD, we observe a rise in weight and BMI with time, whether they resumed GHRT or not. Previous studies have found an effect of $\mathrm{GH}$ treatment on body composition in patients with CO-GHD or adult onset-GHD, but not on weight or BMI (25). However, we have not found a significant modification of body composition with time, but there is an important lack of data, especially in the untreated group.

This study made us aware of the number of missing explorations during adulthood in patients with persistent GHD from childhood. For instance, although all patients were followed in the same adult department, some of them did not have an evaluation of body composition or BMD by DEXA, especially patients who did not resume GHRT. Even more data were missing concerning the cardiovascular explorations (cardiac sonography, supra-aortic root Doppler), making it impossible to study those parameters. Metabolic parameters were more uniformly explored.

We observe an improvement in lipid profile over time only in GHD patients who receive GHRT during adulthood (group 1), which is in agreement with previously published studies $(26,27,28)$. We did not find a difference in lipid profile according to IGF1 SDS values. Even though results are controversial, others studies have found that a rise in IGF1 under GHRT during transition is associated with a drop in TC and LDL-c (29). An explanation for the fact that we have found a significant variation in some parameters according to $\mathrm{GH}$ treatment status, but not according to IGF1 status ( $<-2$ or $\geq-2$ SDS), could lie in our methodology. Indeed, groups of treatment were elaborated using all the visits (consult and hospitalization), as the IGF1 status groups were determined from a unique dosage on day of evaluation, which might not be adequately representative of its long-term level.

FG tends to rise in GHD patients receiving GHRT during adulthood (group 1), but it also does in untreated GHD patients (group 2). On the other hand, $\mathrm{HbA} 1 \mathrm{c}$ tends to be lower in group 1 than that in group 2 after a few years of the follow-up (EVAL2). The net effect of GHRT on insulin resistance is difficult to predict. GHRT lowers fat mass, and increasing IGF1 improves insulin sensitivity (30). However, GH also has direct insulin antagonistic effects in the liver and other tissues (31). A meta-analysis of placebo-controlled studies showed that GHRT was associated with a slight rise in both fasting glucose and fasting insulin levels (32).

The variations observed in the metabolic parameters are not explained by the etiology of the GHD, and in particular, no significant difference is found between patients with a history of craniopharyngioma and the other patients.

We observe a significant rise in spine and hip BMD in GHD adult patients under GHRT (group 1), which is in agreement with previously published data $(8,24,33)$. GHRT has an overall anabolic effect on bone, but its effects are complex and the results are biphasic (6). Levels of osteocalcin are higher in patients with IGF1 values $\geq-2$ SDS than that in patients with IGF1 $<-2$ SDS, which is consistent with the results from another study (4).

There is a strong correlation between the number of deficits associated with GHD, lipid profile, weight, BMI, and percentage of fat mass. A positive correlation has been found between time off GHRT during transition and TC, LDL-c, and TG in patients with non-idiopathic CO-GHD, who are more inclined to have associated deficits (4). It is possible that the presence of associated deficits increases the deleterious effects of GHD on lipid profile. A study compared patients with isolated and associated CO-GHD, and concluded that in GHD patients, associated deficits aggravate BMI, waist circumference, and lower IGF 1 levels, but GHRT ameliorates these parameters in the same extent in isolated and associated GHD (34).

In multivariate analysis, the only variable significantly associated to lipid profile, weight, and BMI, is the gonadotropic deficit. Deleterious effects on BMI or lipid profile in patients with either insufficient treatment for congenital hypogonadotropic hypogonadism or with anti-androgenic drugs for prostate cancer have been found $(35,36)$. Besides, estrogen substitution in women with gonadotropic and somatotropic deficits leads to hepatic resistance to $\mathrm{GH}$ action and thus to a decrease in IGF1 level compared with women without estrogen (37). In our study, women with gonadotropic deficit received oral estrogen substitution therapy, thus potentially have lower levels of IGF1, explaining higher levels of TC and LDL-c. We also observe a significant association between corticotropic deficit and a higher FG, as well as a higher fat mass percentage. We could hypothesize that, as previously reported, glucocorticoid replacement therapy increases morning insulin resistance and abdominal fat mass and weight (38). Finally, we found a positive correlation between thyreotropic deficit and LDL-c. Effects of hypothyroidism on lipid profile are well known. However, in our study, most patients with thyreotropic deficit are adequately supplemented in $\mathrm{L}_{-} \mathrm{T}_{4}$. We could hypothesize that because the conversion of $\mathrm{T}_{4}$ into $\mathrm{T}_{3}$ is reduced in untreated GHD patients (39), it is possible that some patients with normal $\mathrm{FT}_{4}$ levels are nevertheless insufficiently supplemented.

In conclusion, important reflections in pediatric and adult endocrinologists concerning the management of CO-GHD patients around and after transition are necessary because real-life practice is far from published recommendations. Impact of GHD on metabolism, body, 
and bone compositions seems inferior to that of other pituitary deficits. More studies, particularly prospective, are needed to further address the issue of the care of CO-GHD patients during and after transition.

\section{Declaration of interest}

The authors declare that there is no conflict of interest that could be perceived as prejudicing the impartiality of the research reported.

\section{Funding}

This research did not receive any specific grant from any funding agency in the public, commercial or not-for-profit sector.

\section{Acknowledgements}

The authors thank Nathalie Gambier for her help in managing the database and Jean-Claude Souberbielle for his helpful advice. On behalf of the Transition GHD Group: Anne-Marie Bertrand, Thierry Billette de Villemeur, Pierre Bougnères, Claire Bouvattier, Raja Brauner, Sylvie Cabrol, Jean-Claude Carel, Mireille. Castanet, JeanLouis Chaussain, Hélène Crosnier, Paul Czernichow, François Doz, Christelle Dufour, Claire Fekete, Isabelle Flechtner, Pierre Frange, Jacques Grill, Muriel Houang, Jean-Claude Job, Chantal Kalifa, AlainPierre Kahn, Josette Lorilloux, Jean Michon, Hélène Pacquement, Christian Pauwels, Raphäl Rappaport, Christian Sainte Rose, Dinane Samara-Boustani, Sylvie Sauvion, Dominique Simon, Philippe Talon, Caroline Thalassinos, Elisabeth Thibaud, Dominique Valteau-Couanet, and Michel Zerah.

\section{References}

1 Molitch ME, Clemmons DR, Malozowski S, Merriam GR \& Vance ML. Evaluation and treatment of adult growth hormone deficiency: an Endocrine Society Clinical Practice Guideline. Journal of Clinical Endocrinology and Metabolism 201196 1587-1609. (doi:10.1210/jc.2011-0179)

2 Cook DM \& Rose SR. A review of guidelines for use of growth hormone in pediatric and transition patients. Pituitary 201215 301-310. (doi:10.1007/s11102-011-0372-6)

3 Conway GS, Szarras-Czapnik M, Racz K, Keller A, Chanson P, Tauber M, Zacharin M \& 1369 GHD to GHDA Transition Study Group. Treatment for 24 months with recombinant human GH has beneficial effect on bone mineral density in young adults with childhood-onset GH deficiency. European Journal of Endocrinology 2009160 899-907. (doi:10.1530/EJE-08-0436)

4 Kołtowska-Häggström M, Geffner ME, Jönsson P, Monson JP, Abs R, Hána V, Höybye C \& Wollmann HA. Discontinuation of growth hormone $(\mathrm{GH})$ treatment during the transition phase is an important factor determining the phenotype of young adults with nonidiopathic childhood-onset GH deficiency. Journal of Clinical Endocrinology and Metabolism 201095 2646-2654. (doi:10. 1210/jc.2009-2013)

5 Johannsson G, Albertsson-Wikland K \& Bengtsson BA. Discontinuation of growth hormone $(\mathrm{GH})$ treatment: metabolic effects in $\mathrm{GH}$-deficient and $\mathrm{GH}$-sufficient adolescent patients compared with control subjects. Swedish Study Group for Growth Hormone Treatment in Children. Journal of Clinical Endocrinology and Metabolism 199984 4516-4524. (doi:10.1210/jc.84.12.4516)

6 Shalet SM, Shavrikova E, Cromer M, Child CJ, Keller E, Zapletalová J, Moshang T, Blum WF, Chipman JJ, Quigley CA et al. Effect of growth hormone $(\mathrm{GH})$ treatment on bone in postpubertal GH-deficient patients: a 2-year randomized, controlled, dose-ranging study. Journal of Clinical Endocrinology and Metabolism 200388 4124-4129. (doi:10.1210/jc.2003030126)

7 Carroll PV, Drake WM, Maher KT, Metcalfe K, Shaw NJ, Dunger DB, Cheetham TD, Camacho-Hübner C, Savage MO \& Monson JP. Comparison of continuation or cessation of growth hormone $(\mathrm{GH})$ therapy on body composition and metabolic status in adolescents with severe GH deficiency at completion of linear growth. Journal of Clinical Endocrinology and Metabolism 200489 3890-3895. (doi:10.1210/jc.2003-031588)

8 Tritos NA, Hamrahian AH, King D, Greenspan SL, Cook DM, Jönsson PJ, Wajnrajch MP, Koltowska-Häggstrom M \& Biller BM. A longer interval without $\mathrm{GH}$ replacement and female gender are associated with lower bone mineral density in adults with childhood-onset GH deficiency: a KIMS database analysis. European Journal of Endocrinology 2012167 343-351. (doi:10.1530/ EJE-12-0070)

9 Colao A, Di Somma C, Salerno M, Spinelli L, Orio F \& Lombardi G. The cardiovascular risk of GH-deficient adolescents. Journal of Clinical Endocrinology and Metabolism $2002 \quad 87$ 3650-3655. (doi:10.1210/jc.87.8.3650)

10 Oliveira JL, Aguiar-Oliveira MH, D'Oliveira A Jr, Pereira RM, Oliveira CR, Farias CT, Barreto-Filho JA, Anjos-Andrade FD, Marques-Santos C, Nascimento-Junior AC et al. Congenital growth hormone $(\mathrm{GH})$ deficiency and atherosclerosis: effects of $\mathrm{GH}$ replacement in GH-naive adults. Journal of Clinical Endocrinology and Metabolism 200792 4664-4670. (doi:10.1210/jc.20071636)

11 Jørgensen JO, Nørrelund H, Vahl N, Juul A, Skakkebaek NE \& Christiansen JS. Continuation of growth hormone therapy versus placebo in transition-phase patients with growth hormone deficiency: impact on body composition, insulin sensitivity, and thyroid function. Journal of Pediatric Endocrinology \& Metabolism 200215 1355-1360.

12 GH Research Society. Consensus guidelines for the diagnosis and treatment of growth hormone (GH) deficiency in childhood and adolescence: summary of the GH Resarch Society. Journal of Clinical Endocrinology and Metabolism 200085 3990-3993. (doi:10.1210/jc.85.11.3990)

13 Clayton PE, Cuneo RC, Juul A, Monson JP, Shalet SM, Tauber M \& European Society of Paediatric Endocrinology. Consensus statement on the management of the GH-treated adolescent in the transition to adult care. European Journal of Endocrinology 2005 152 165-170. (doi:10.1530/eje.1.01829)

14 Attanasio AF \& Shalet SM. Growth hormone and the transition from puberty into adulthood. Endocrinology and Metabolism Clinics of North America 200736 187-201. (doi:10.1016/j.ecl.2006. 11.002)

15 Viner RM. Transition of care from paediatric to adult services: one part of improved health services for adolescents. Archives of Disease in Childhood 200893 160-163. (doi:10.1136/adc.2006. 103721)

16 Godbout A, Tejedor I, Malivoir S, Polak M \& Touraine P. Transition from paediatric to adult healthcare-assessment of specific needs of patients with chronic endocrine conditions. Hormone Research in Paediatrics 201278 247-255. (doi:10.1159/000343818)

17 Shemesh E, Annunziato RA, Arnon R, Miloh T \& Kerkar N. Adherence to medical recommendations and transition to adult services in pediatric transplant recipients. Current Opinion in Organ Transplantation 201015 288-292. (doi:10.1097/MOT.0b013 e32833984a5)

18 Kipps S, Bahu T, Ong K, Ackland FM, Brown RS, Foxt CT, Griffin NK, Knight AH, Mann NP, Neil HAW et al. Current methods of transfer of young people with type 1 diabetes to adult services. Diabetic Medicine 200219 649-654. (doi:10.1046/j.1464-5491. 2002.00757.x)

19 Attanasio AF, Shavrikova E, Blum WF, Cromer M, Child CJ, Paskova M, Lebl J, Chipman JJ, Shalet SM \& Hypopituitary Developmental Outcome Study Group. Continued growth hormone (GH) treatment after final height is necessary to complete somatic 
development in childhood-onset GH-deficient patients. Journal of Clinical Endocrinology and Metabolism 200489 4857-4862. (doi:10.1210/jc.2004-0551)

20 Radovick S \& DiVall S. Approach to the growth hormone-deficient child during transition to adulthood. Journal of Clinical Endocrinology and Metabolism 200792 1195-1200. (doi:10.1210/ jc.2007-0167)

21 Gelwane G, Garel C, Chevenne D, Armoogum P, Simon D, Czernichow P \& Léger J. Subnormal serum insulin-like growth factor-I levels in young adults with childhood-onset nonacquired growth hormone $(\mathrm{GH})$ deficiency who recover normal $\mathrm{GH}$ secretion may indicate less severe but persistent pituitary failure. Journal of Clinical Endocrinology and Metabolism 2007923788 3795. (doi:10.1210/jc.2007-1003)

22 Ho KK \& 2007 GH Deficiency Consensus Workshop Participants. Consensus guidelines for the diagnosis and treatment of adults with GH deficiency II: a statement of the GH Research Society in association with the European Society for Pediatric Endocrinology, Lawson Wilkins Society, European Society of Endocrinology, Japan Endocrine Society, and Endocrine Society of Australia. European Journal of Endocrinology 2007157 695-700. (doi:10.1530/EJE07-0631)

23 Cook DM, Yuen KC, Biller BM, Kemp SF \& Vance ML. American Association of Clinical Endocrinologists medical guidelines for clinical practice for growth hormone use in growth hormone deficient adults and transition patients - 2009 update. Endocrine Practice 200915 (Suppl 2) 1-29.

24 Van der Sluis IM, Boot AM, Hop WC, De Rijke YB, Krenning EP \& de Muinck Keizer-Schrama SM. Long-term effects of growth hormone therapy on bone mineral density, body composition, and serum lipid levels in growth hormone deficient children: a 6-year follow-up study. Hormone Research 200258 207-214. (doi:10.1159/000066262)

25 Ezzat S, Fear S, Gaillard RC, Gayle C, Landy H, Marcovitz S, Mattioni T, Nussey S, Rees A \& Svanberg E. Gender-specific responses of lean body composition and non-gender-specific cardiac function improvement after $\mathrm{GH}$ replacement in $\mathrm{GH}-$ deficient adults. Journal of Clinical Endocrinology and Metabolism $2002872725-2733$ (Erratum in: Journal of Clinical Endocrinology and Metabolism 87 4461). (doi:10.1210/jc.87.6.2725)

26 Verhelst J \& Abs R. Cardiovascular risk factors in hypopituitary GH-deficient adults. European Journal of Endocrinology 2009161 (Suppl 1) S41-S49. (doi:10.1530/EJE-09-0291)

27 Abs R, Feldt-Rasmussen U, Mattsson AF, Monson JP, Bengtsson BA, Góth MI, Wilton P \& Koltowska-Häggström M. Determinants of cardiovascular risk in 2589 hypopituitary GH-deficient adults - a KIMS database analysis. European Journal of Endocrinology 2006155 79-90. (doi:10.1530/eje.1. 02179)

28 Monson JP, Jönsson P, Koltowska-Häggström M \& Kourides I. Growth hormone $(\mathrm{GH})$ replacement decreases serum total and LDL-cholesterol in hypopituitary patients on maintenance HMG CoA reductase inhibitor (statin) therapy. Clinical Endocrinology 200767 623-628. (doi:10.1111/j.1365-2265.2007.02935x)

29 Fideleff HL, Jonsson B, Koltowska-Häggström M, Boguszewski MC, Wilton P \& Boquete HR. GH deficiency during the transition period: clinical characteristics before and after GH replacement therapy in two different subgroups of patients. Journal of Pediatric Endocrinology \& Metabolism 201225 97-105.

30 Clemmons DR. The relative roles of growth hormone and IGF1 in controlling insulin sensitivity. Journal of Clinical Investigation 2004 $11325-27$.

31 Moller N \& Jorgensen JO. Effects of growth hormone on glucose, lipid, and protein metabolism in human subjects. Endocrine Reviews 200930 152-177. (doi:10.1210/er.2008-0027)

32 Maison P, Griffin S, Nicoue-Beglah M, Haddad N, Balkau B, Chanson P \& Metaanalysis of Blinded, Randomized, PlaceboControlled Trials . Impact of growth hormone (GH) treatment on cardiovascular risk factors in GH-deficient adults: a meta-analysis of blinded, randomized, placebo-controlled trials. Journal of Clinical Endocrinology and Metabolism 200489 2192-2199. (doi:10.1210/jc.2003-030840)

33 Drake WM, Carroll PV, Maher KT, Metcalfe KA, CamachoHübner C, Shaw NJ, Dunger DB, Cheetham TD, Savage MO \& Monson JP. The effect of cessation of GH therapy on bone mineral accretion in GHD adolescents at the completion of linear growth. Journal of Clinical Endocrinology and Metabolism $2003 \mathbf{8 8} 1658$ 1663. (doi:10.1210/jc.2002-021541)

34 Abs R, Mattsson AF, Bengtsson BA, Feldt-Rasmussen U, Góth MI, Koltowska-Häggström M, Monson JP, Verhelst J, Wilton P \& KIMS Study Group . Isolated growth hormone (GH) deficiency in adult patients: baseline clinical characteristics and responses to $\mathrm{GH}$ replacement in comparison with hypopituitary patients. A subanalysis of the KIMS database. Growth Hormone $\mathcal{E}$ IGF Research 200515 349-359. (doi:10.1016/j.ghir.2005.06.018)

35 Laitinen EM, Hero M, Vaaralahti K, Tommiska J \& Raivio T. Bone mineral density, body composition and bone turnover in patients with congenital hypogonadotropic hypogonadism. International Journal of Andrology 201235 534-540. (doi:10.1111/j.13652605.2011.01237.x)

36 Braga-Basaria M, Muller DC, Carducci MA, Dobs AS \& Basaria S. Lipoprotein profile in men with prostate cancer undergoing androgen deprivation therapy. International Journal of Impotence Research 200618 494-498. (doi:10.1038/sj.ijir.3901471)

37 Mah PM, Webster J, Jönsson P, Feldt-Rasmussen U, KoltowskaHäggström M \& Ross RJ. Estrogen replacement in women of fertile years with hypopituitarism. Journal of Clinical Endocrinology and Metabolism 200590 5964-5969. (doi:10.1210/jc.2005-1207)

38 Al-Shoumer KA, Beshyah SA, Niththyananthan R \& Johnston DG. Effect of glucocorticoid replacement therapy on glucose tolerance and intermediary metabolites in hypopituitary adults. Clinical Endocrinology 199542 85-90. (doi:10.1111/j.1365-2265.1995. tb02602.x)

39 Filipsson H \& Johannsson G. GH replacement in adults: interactions with other pituitary hormone deficiencies and replacement therapies. European Journal of Endocrinology 2009 161 (Suppl 1) S85-S95. (doi:10.1530/EJE-09-0319)

Received 7 March 2013

Revised version received 31 July 2013

Accepted 12 August 2013 